\title{
A QUIIMICA DOS TECIDOS TÊXTEIS ABORDADA POR MEIO DE ESTUDO DE CASOS
}

\section{THE TEXTILE FABRICS CHEMISTRY APPROACHED BY MEANS OF CASE STUDY}

\author{
Valesca Vargas Vieira \\ Universidade Federal de Santa Maria, valesk.vvv@gmail.com \\ Mara Elisa Fortes Braibante \\ Universidade Federal de Santa Maria, maraefb@gmail.com
}

\section{Resumo}

Os professores ao longo dos anos vêm enfrentando grandes desafios no ensino, principalmente na área das ciências como a Química, pois os alunos a consideram muitas vezes distantes do seu dia a dia. Nesta perspectiva o presente trabalho propõe utilizar uma contextualização por meio da temática "Tecidos Têxteis" aliada aos estudos de casos, com o intuito de tornar os conteúdos de química abordados mais próximos da realidade do estudante e desta maneira auxiliá-los na construção do seu conhecimento. Neste contexto, este trabalho foi desenvolvido com estudantes da terceira série do ensino médio, a partir de uma proposta aplicando a metodologia de estudo de casos, tendo como finalidade de favorecer a aprendizagem. Por meio desta metodologia buscou-se desenvolver a capacidade de tomada de decisão e resolução de problemas por parte dos estudantes, bem como a comunicação oral e escrita, o estímulo a pesquisa e capacidade de trabalhar em grupo.

Palavras-chave: Tecidos têxteis, Estudo de Caso, Ensino de Química.

\section{Abstract}

The teachers over the years have faced great challenges in teaching, especially in the area of sciences as Chemistry, since students often consider distant from their everyday life. In this perspective, the present paper proposes to use a contextualization through the theme "Textile Fabrics" associated to the case studies, in order to make the chemistry contents approached closer to the student's reality and, in this way, help in the construction of their knowledge. In this context, this paper was developed with students from the last year of high school, based on a proposal applied to the presented methodology with a purpose to favor learning. By means of this methodology, we try to develop the capacity for decision making and problem solving of students, as well as oral and written communication, stimulating also the research and ability to work in group.

Keywords: Textile Fabrics, Case Study, Teaching Chemistry. 


\section{Introdução}

Facilitar e auxiliar a compreensão dos conteúdos científicos é um desafio cada vez maior para os professores, principalmente para a área das exatas, como a Química, que muitas vezes é considerada difícil, abstrata e distante da realidade dos estudantes.

De acordo com as diretrizes apresentadas nas Orientações Curriculares para o Ensino Médio (BRASIL, 2006), um professor deve pensar na melhor forma para trabalhar os conceitos de Química, tentando ao máximo relacioná-los com a realidade dos seus alunos. O mesmo documento ressalta que uma das alternativas para estabelecer essas relações é por meio do desenvolvimento dos conteúdos curriculares de forma contextualizada, relacionados com o contexto social dos educandos. Assim, os conhecimentos adquiridos se tornam significativos e duradouros, de acordo com Moreira (1999) a partir das ideias de Ausubel, descrevendo que esta é uma maneira que possibilita a ancoragem do conhecimento preexistente com o que está sendo formado (novo) na estrutura cognitiva dos alunos. Nesta perspectiva, esses aspectos corroboram com Silva e Marcondes, que destacam:

A contextualização se apresenta como um modo de ensinar conceitos das ciências ligados à vivência dos alunos seja ela pensada como recurso pedagógico ou como princípio norteador do processo de ensino. Então, trata-se de pensar numa abordagem que busque estreitar a relação entre conceitos e contextos, com vistas a ensinar para a formação cidadã (SILVA; MARCONDES, 2014, p.16).

Assim, uma maneira de contextualizar os conceitos científicos de Química, se dá através de uma abordagem temática, a qual é realizada, segundo Santos e colaboradores (2004), para fornecer subsídios para os estudantes compreenderem os processos químicos envolvidos nas diferentes transformações, possibilitando discutirem as suas implicações tecnológicas e os efeitos que tal temática traz para a sociedade, melhorando a qualidade de vida das pessoas. Segundo Marcondes (2008), o tema escolhido deve permitir o estudo da realidade, para que o estudante perceba a importância da temática para si e para todo o grupo social ao qual está inserido, dando significado ao seu aprendizado.

A utilização de temas também é uma alternativa indicada pelas Orientações Curriculares para o Ensino Médio (BRASIL, 2006), pois permite relacionar os conteúdos a serem ensinados com o dia a dia do estudante e se torna um aliado dos professores para auxiliar no processo de ensino-aprendizagem. Braibante e Pazinato (2014, p. 820) afirmam que "a abordagem de temáticas no ensino de química visa favorecer o processo de ensino e aprendizagem e contribuir para a formação do caráter cidadão dos alunos".

Nesta perspectiva, o presente trabalho propõe a temática "Tecidos Têxteis" para ser abordada no ensino de Química, pois é um assunto presente no dia a dia de todos os estudantes, porém é pouco explorado no que se refere à composição química dos tecidos, formas de obtenção, processo de produção dos tecidos, que compõem roupas, calçados e acessórios. Sendo assim, esta temática torna-se apropriada para ser utilizada na contextualização do ensino de Química, pois permite relacionar muitos conceitos químicos com a realidade dos estudantes, tornando esses conteúdos mais significativos. Desta forma, escolheu-se para desenvolvimento e aplicação deste trabalho uma proposta 
diferenciada, por meio da metodologia de estudo de casos a qual torna-se uma aliada para complementar o ensino de conteúdos científicos, com o propósito de auxiliar os estudantes envolvidos, na construção do seu conhecimento.

A seguir, descreveremos algumas possíveis relações entre a química e a temática "Tecidos Têxteis" no ensino de Química, uma breve revisão teórica sobre estudo de casos, sua aplicação e os resultados obtidos neste trabalho.

\section{A Química que vestimos}

Todos os dias utilizamos tecidos, os quais estão presentes em nossas roupas, calçados, casas, acessórios, carros, entre outros. Mas será que paramos para pensar na variedade de cores, texturas, tipos e na sua composição Química? Como teriam surgido? Como são produzidos? E como são elaboradas as estampas? Quais são os diferentes tipos de tecidos?

Segundo Andrade, Correa e Silva (2001), tecido é um produto manufaturado, que resulta do entrelaçamento, de forma ordenada ou desordenada, de fios ou fibras têxteis. De acordo com Pereira (2009) tecido é um material à base de fios de fibra natural ou não natural, que dependendo de como são confeccionados possuem várias aplicações, no vestuário, na decoração, para limpeza, bem como para o uso medicinal.

Para compreender o processo de formação de um tecido é importante conhecer a cadeia produtiva têxtil que tem vários segmentos (Figura 1). De forma simplificada, essa cadeia é iniciada com a obtenção da matéria-prima que são as fibras naturais e não naturais, depois ocorre o processo de fiação para a obtenção do fio, que serão então tramados de maneiras diferentes pela tecelagem ou malharia. Após, ocorre o beneficiamento que envolve um conjunto de operações que um fio ou tecido é submetido, para estar apto para a confecção, como: tingimento, engomagem, retorção, entre outros. Depois de confeccionadas, as peças de vestuário, artigos para o lar ou artigos técnicos e industriais chegam ao consumidor final (SANCHES, 2006; SILVA, 2002).

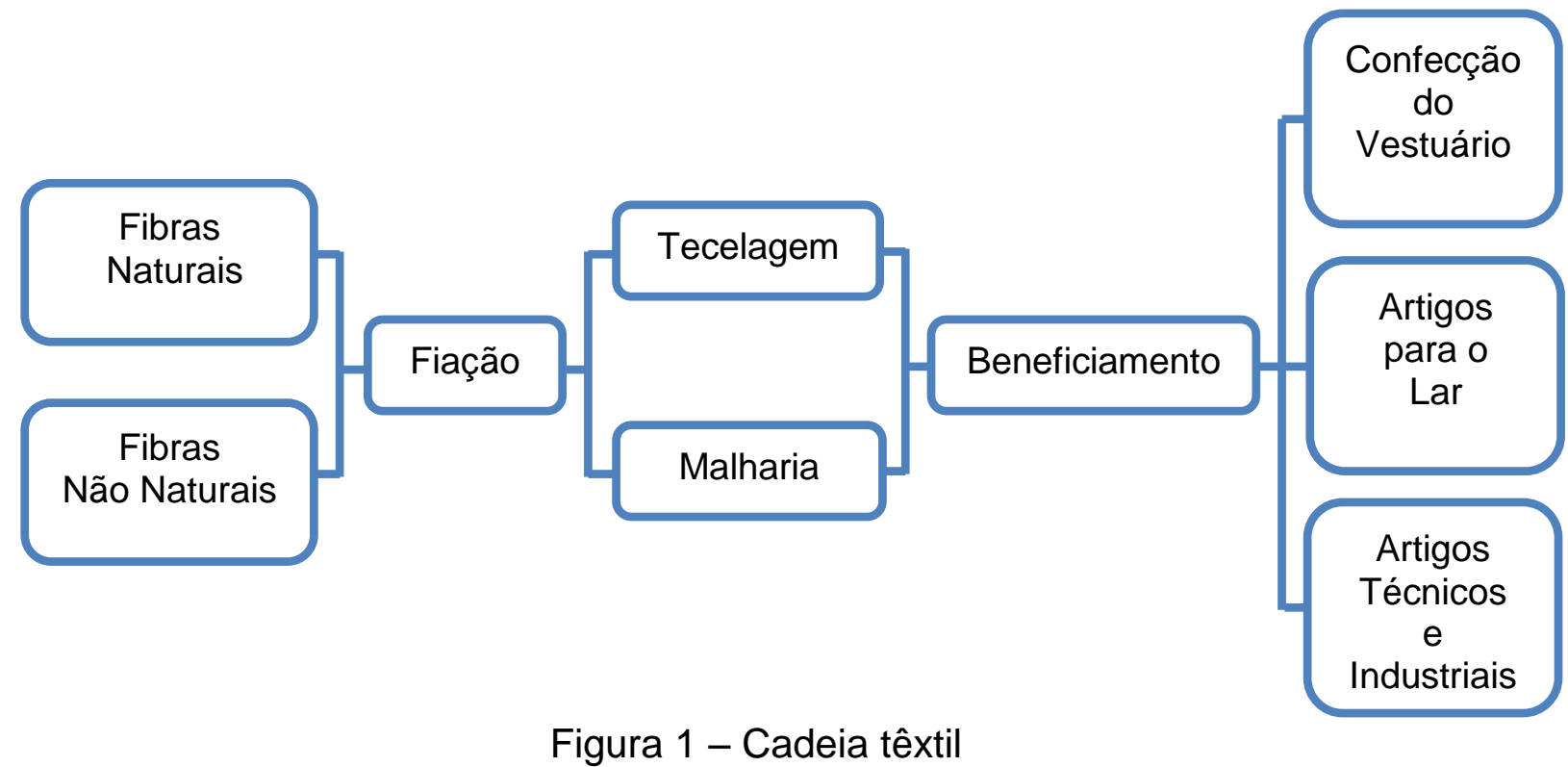

Fonte: Autores. 
Os tecidos são obtidos a partir da trama dos fios formados pelas fibras naturais e não naturais. Mas o que é uma fibra têxtil? Qual é sua composição química? Como teriam surgido os primeiros tecidos?

Segundo Barbosa e colaboradores (2004, p. 81), "fibra têxtil é um material que, submetido a um processo de fabricação, pode ser transformado em fio para ser utilizado em produtos têxteis ou em usos industriais". De acordo com o CONMETRO (2008) as fibras têxteis apresentam características tais como: comprimento, diâmetro, flexibilidade, suavidade, elasticidade, resistência, tenacidade e espessura que as tornam aptas a aplicações têxteis.

As fibras têxteis podem ser divididas em naturais e não naturais. As fibras naturais são aquelas encontradas na natureza, obtidas de fontes orgânicas vegetais que são constituídas de celulose (semente, caule, folhas e frutos) ou animais que são formadas por proteínas (derme ou secreção) (BARBOSA et al., 2004; GUIMARÃES, 2014; SORGER e UDALE, 2009). As fibras não naturais também conhecidas como fibras químicas ou manufaturadas são aquelas produzidas por processos industriais, as artificiais são obtidas a partir do polímero natural de celulose e as sintéticas utilizam resinas derivadas do petróleo como matéria-prima, formando os polímeros (BARBOSA et al., 2004; MIÚRA e MUNOZ, 2015; ROMERO et al., 1995).

As fibras naturais vegetais são compostas principalmente por celulose, por isso também são conhecidas como fibras celulósicas naturais (MIÚRA e MUNOZ, 2015). Todas essas fibras possuem uma composição química muito semelhante, como podemos observar na Tabela 1, as fibras naturais vegetais são substâncias polares compostas principalmente por celulose, hemicelulose, lignina e pequenas quantidades de pectina.

Tabela 1: Composição química de algumas fibras comercialmente importantes.

\begin{tabular}{c|c|c|c|c}
\hline Fibra & $\begin{array}{c}\text { Celulose } \\
(\%)\end{array}$ & $\begin{array}{c}\text { Hemicelulose } \\
(\%)\end{array}$ & $\begin{array}{c}\text { Lignina } \\
(\%)\end{array}$ & $\begin{array}{c}\text { Pectina } \\
(\%)\end{array}$ \\
\hline Algodão & 92 & 6 & - & $<1$ \\
\hline Juta & 72 & 13 & 13 & 4 \\
\hline Linho & 81 & 14 & 3 & 2 \\
\hline Sisal & 73 & 13 & 11 & 1 \\
\hline Cânhamo & 74 & 18 & 4 & 2 \\
\hline Fibra de coco & 43 & $<1$ & 45 & 8 \\
\hline Rami & 76 & 15 & 1 & \\
\hline Palha & 40 & 28 & 17 & \\
\hline Paina & 13 & & & \\
\hline
\end{tabular}

Fonte: (MWAIKAMBO e ANSELL, 2002, p. 2223, tradução nossa).

Apesar dessas fibras possuírem uma composição química muito semelhante, as propriedades físicas, mecânicas e a aparência diferem muito uma das outras, as maiores diferenças podem ser observadas quanto ao toque e maciez desses tecidos. Como semelhanças podem ser destacadas a grande capacidade de absorção, a hidrofilidade, boa condutibilidade térmica, reduzida resistência ao amarrotamento, entre outras (PEREIRA, 2009). De acordo com Leão (2008) a composição química da fibra varia um 
pouco dependendo da região de cultivo, tipo de solo, condições climáticas, variedade da espécie, dentre outros fatores.

As fibras naturais vegetais são extraídas de sementes, folhas, caules ou frutos, as que estarão descritas a seguir, formam os tecidos de algodão, linho e sisal.

\section{Algodão}

O algodão é uma das fibras naturais vegetais mais antigas cultivadas pelo homem, porém, a época que iniciou o seu cultivo com fins têxteis é incerta. Na Índia há aproximadamente 3 mil anos a.C. já era conhecido entre os povos, Heródoto falava em árvores contendo lã, melhor e mais bonita que a dos animais. Foram os mercadores indianos que levaram o algodão ao Egito, África, Macedônia, Grécia, Roma, Europa e mesmo passado tanto tempo, ainda se mantém como a principal fibra têxtil do mundo (PEZZOLO, 2007).

O algodão é produzido pelo algodoeiro, planta da família das Malváceas, de algumas espécies do gênero Gossypium, as suas fibras crescem aderidas às sementes dentro de uma cápsula, ou capulho que abre quando maduro (MIÚRA e MUNOZ, 2015; PEZZOLO, 2007)

O algodão é constituído por mais de $90 \%$ de celulose, a molécula de celulose é um homopolissacarídeo linear, não ramificado de glicoses unidas por ligações $\beta-1,4$. Para compreender melhor a composição da celulose é importante saber que ela é um carboidrato e que estes estão divididos em três classes principais: os monossacarídeos, os oligossacarídeos e os polissacarídeos (BERG, TYMOCZKO, STRYER, 2010; NELSON e COX, 2006).

Os monossacarídeos são a menor unidade estrutural de um carboidrato, são cetonas ou aldeídos que contém um ou mais grupos hidroxilas na sua molécula (NELSON e COX, 2006), um exemplo é a molécula de glicose (Figura 2) na qual estão presentes as funções orgânicas álcool e aldeído, quando o grupo carbonila é de um aldeído a molécula é classificada como aldose.<smiles>O=CC(O)C(O)C(O)CO</smiles>

Figura 2 - Representação da molécula de glicose Fonte: Autores.

$\mathrm{Na}$ ciclização dos monossacarídeos ocorre o ataque do oxigênio ao carbono do grupo carbonila. A reação entre aldeído e álcool forma hemiacetais, resultando em um novo centro quiral no carbono da carbonila (NELSON e COX, 2006). A ciclização da cadeia aberta da glicose ocorre quando a hidroxila livre do C-5 reage com o grupo aldeído 
do C-1 e este carbono passa a ser um centro assimétrico, resultando em dois diastereoisômeros, denominados a e $\beta$, conforme Figura 3 (BERG, TYMOCZKO, STRYER, 2010).
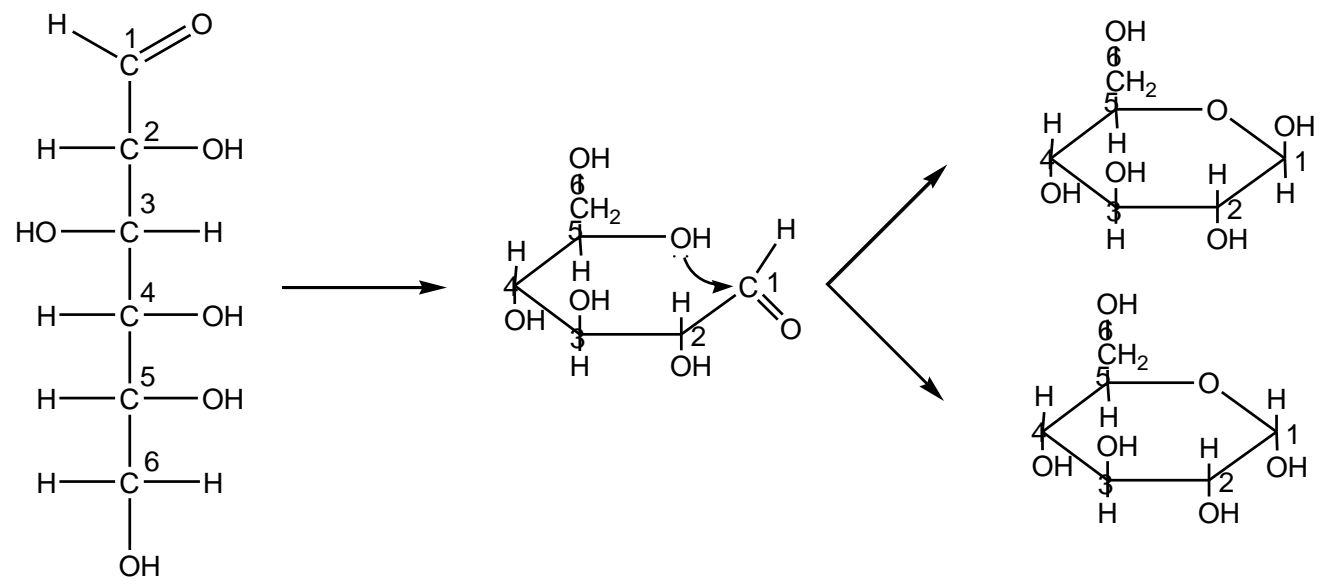

Figura 3 - Ciclização da molécula de D-glicose Fonte: Autores.

A celulose é um polissacarídeo, ou seja, carboidrato formado por centenas ou milhares de monossacarídeos em uma única molécula. A celulose tem de 10.000 a 15.000 unidades de D-glicose em sua composição, que estão unidas por ligações glicosídicas do tipo $(\beta-1,4)$ como representada na Figura 4 (NELSON e COX, 2006). Segundo Berg e colaboradores (2010, p. 316) "a configuração $\beta$ permite à celulose formar cadeias retilíneas muito grandes, as fibrilas são formadas por cadeias paralelas que interagem umas com as outras por ligações hidrogênio".

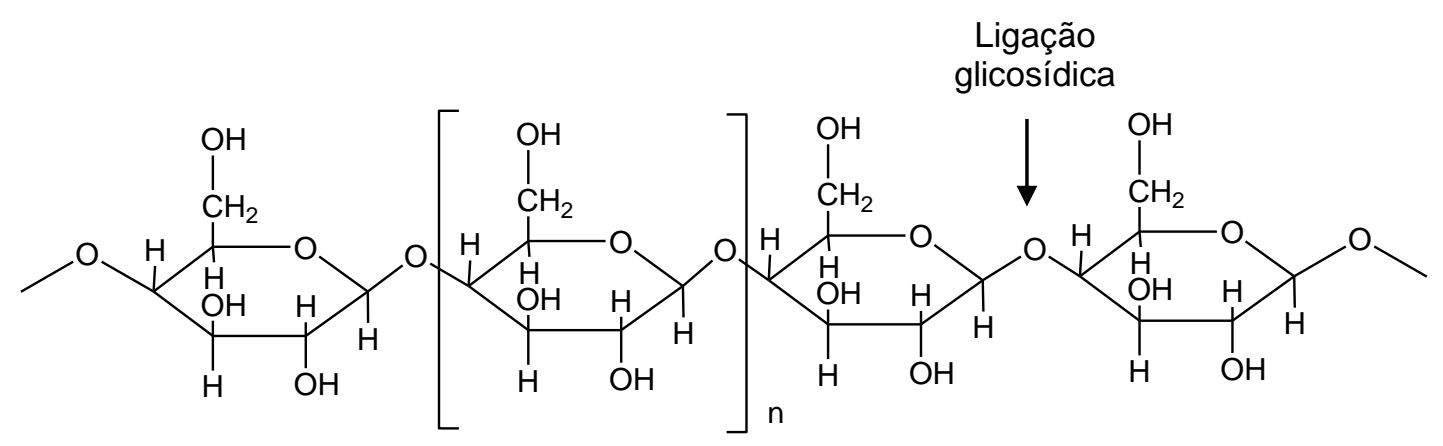

Figura 4 - Representação da molécula de glicose e da ligação glicosídica Fonte: Autores.

Além da molécula de celulose presente no tecido de algodão, suas fibras também são compostas por hemicelulose e lignina.

A hemicelulose é um polissacarídeo com baixa massa molecular, que está normalmente associado à celulose na parede celular, porém em menor quantidade, favorecendo a elasticidade e evitando que as microfibrilas de celulose se toquem. É constituída por vários monossacarídeos, incluindo carboidratos de 5 e 6 carbonos, 
pentoses e hexoses que possuem, respectivamente, as fórmulas gerais $\mathrm{C}_{5} \mathrm{H}_{8} \mathrm{O}_{4}$ e $\mathrm{C}_{6} \mathrm{H}_{10} \mathrm{O}_{5}$ (BENINI, 2011; FENGEL e WEGENER, 1989).

Já a lignina que também está presente na parede celular, é um polímero polifenólico que contém unidades estruturais de fenilpropano (SILVA et al., 2009; FENGEL e WEGENER, 1989). Segundo Nelson e Cox (2006, p. 850) "a estrutura do polímero lignina é complexa e não está bem esclarecida".

O algodão constitui-se predominantemente de celulose possuindo cadeias mais ordenadas com cristalinidade em torno de $70 \%$ e cerca de $30 \%$ são amorfas. Essa composição the confere características desejáveis como a elevada capacidade de absorção de água, pois as hidroxilas $(-\mathrm{OH})$ que não fazem parte dos feixes de fibras rígidas e insolúveis formadas pelas longas cadeias de celulose atraem as moléculas de água (COUTEUR e BURRESON, 2006; PEREIRA, 2009).

Assim, foi possível conhecer a composição química da fibra que forma o tecido de algodão, o qual é muito macio sendo por isto utilizado para a confecção de roupas em geral, principalmente roupas de bebê, por ser um tecido de toque mais suave, também são fabricados, pijamas, roupas de cama, mesa e banho.

\section{Linho}

O linho é uma das mais antigas fibras do mundo, as planícies do Nilo servem de leito para o cultivo desta planta há cerca de 8 mil anos, os tecidos confeccionados com ele vestiam faraós e rainhas egípcias. Esse material nobre espalhou-se pela Europa, sendo a primeira planta têxtil cultivada na Europa, mas ainda hoje tem grande demanda mundial em função de suas características.

A planta que produz as fibras com as quais se fabrica o tecido de linho é chamada cientificamente de Linum usitatissimum, é uma fibra natural existente na entrecasca do caule da planta da família das lináceas, as variedades de linho podem alcançar entre 90 e $120 \mathrm{~cm}$ de altura (MIÚRA e MUNOZ, 2015; FERRI, 1976). Conforme podemos observar na Tabela 1, o linho possui $81 \%$ de celulose em sua constituição, enquanto que o algodão possui $92 \%$, apesar desta diferença o comportamento químico do linho e do algodão é semelhante (CARVALHO, 2011).

O linho é uma fibra forte, porém, possui péssima recuperação a dobra, compressão ou amarrotamento, o que ocasiona a formação de rugas, por esta razão, os tecidos de linho, ao serem dobrados muitas vezes na mesma região, tem a tendência de romper. Como as fibras de linho não "encolhem" nem "alongam", os tecidos confeccionados com elas, também estão sujeitos a estas situações. O linho é um bom condutor de calor, esta é uma das principais razões que explicam o porquê dos lenços de linho parecerem "frios" (KUASNE, 2008).

A fibra de linho que irá formar o tecido também é composta por celulose, hemicelulose e lignina, além disso, possui a pectina em sua composição.

A pectina é um polissacarídeo encontrado na parede celular das células vegetais, com cerca de 150 a 500 unidades de ácido galacturônico que podem ser parcialmente 
esterificados com grupos metoxílicos (BOBBIO, 1992). A Figura 5 apresenta o ácido galacturônico (5a) e ácido galacturônico esterificado (5b) que formam a pectina, possuem em sua estrutura as funções orgânicas, ácido carboxílico, éster, éter e álcool.

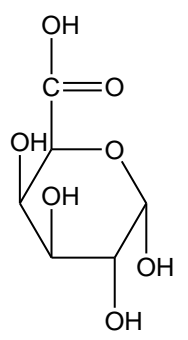

$5 a$

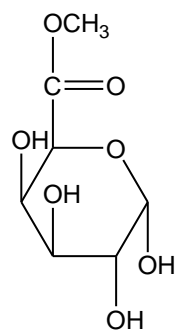

$5 b$

Figura 5 - Estruturas do ácido galacturônico (5a) e ácido galacturônico esterificado (5b) Fonte: Autores.

Para formar a pectina as unidades de ácido galacturônico e ácido galacturônico esterificados são unidas por ligações glicosídicas do tipo $\alpha-1,4$, como representada na Figura 6, é uma ligação covalente formada quando um grupo hidroxila de uma molécula de açúcar reage com o átomo de carbono anomérico da outra molécula, a partir de um hemiacetal e de um álcool resultando na formação de um acetal (NELSON e COX, 2006).

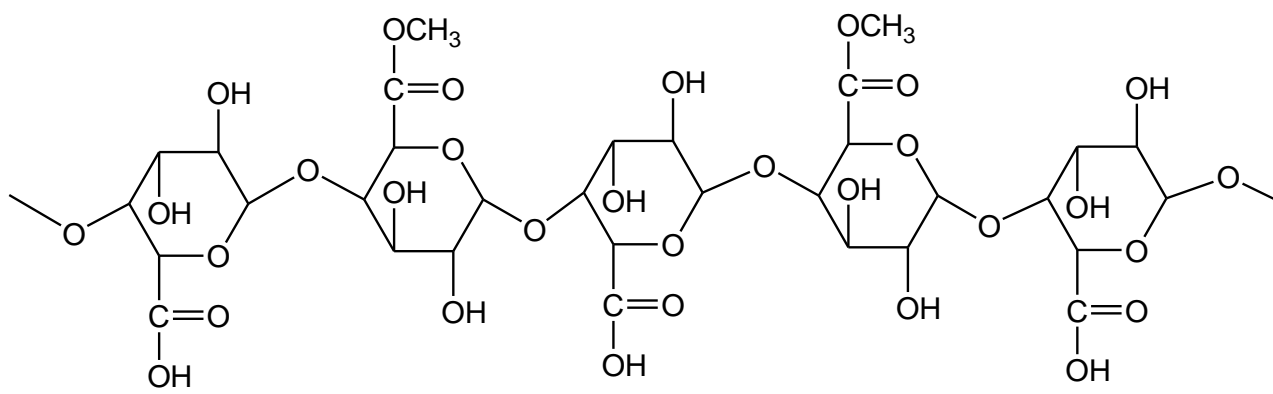

Figura 6 - Estrutura geral da pectina

Fonte: Adaptação de Brandão e Andrade (1999, p. 39).

Portanto, esta é a composição química da fibra que irá formar o tecido de linho muito utilizado para a fabricação de roupas, guardanapos, toalhas de mesa, utensílios de decoração, ainda no século XVII segundo Pezzolo (2007) foi utilizado para a elaboração da crinolina, um tecido armado, feito de crina de cavalo e linho, usado em armações para saias, também usado pelos egípcios para fazerem as faixas com as quais enrolavam as múmias.

\section{Sisal}

O sisal é uma planta originária do México, no Brasil os primeiros bulbilhos da planta foram trazidos provavelmente da Flórida, por meio de uma firma americana e introduzidos na Bahia em 1903, pelo Comendador Horácio Urpia Júnior nos municípios de Madre de 
Deus e Maragogipe, sendo difundido na Paraíba e depois por outros lugares no país (CORREIA, 2011).

A fibra de sisal também é uma fibra natural vegetal que tem a mesma composição química do linho, composta por celulose, hemicelulose, lignina e pectina.

No entanto a fibra do sisal é extraída das folhas da Agave sisalana pertencente a família das Agaváceas, seu comprimento varia entre 60 e $160 \mathrm{~cm}$ e apresenta excelente resistência à ruptura e ao alongamento (KUASNE, 2008; FERRI, 1976)

Segundo Correia (2011) o ciclo de transformação do sisal em fios que formarão os tecidos, tem início quando a planta tem 3 anos, ou quando as folhas atingem $140 \mathrm{~cm}$ de comprimento, que desta forma, as fibras terão de 90 a $120 \mathrm{~cm}$. As folhas são cortadas a cada 6 meses durante toda a vida da planta que pode ser 6 a 7 anos, esta é uma planta muito resistente que se adaptou bem à aridez e ao sol intenso do sertão nordestino.

A fibra de sisal e o tecido formado por ela são utilizados para a confecção de sacolas, sandálias, bolsas e chapéus, principalmente para praia, cestos, cintos, solados de alpargatas, na fabricação de cordas, barbantes e na tecelagem de tapetes e cortinas decorativos, entre outros. Estas fibras são empregadas também na indústria automobilística em substituição a fibra de vidro, tendo como vantagem a maior capacidade de absorção da transpiração humana, o que resulta em maior conforto para os profissionais que passam longos períodos sentados nos veículos automotivos.

\section{Estudo de casos}

Essa metodologia está baseada no método de Aprendizado Baseado em Problemas (ABP), conhecido também como Problem Based Learning (PBL). Sua utilização surgiu no final dos anos sessenta na Escola de Medicina da Universidade de McMaster localizada em Ontário, Canadá e logo se espalhou por faculdades de medicina de diversos países, alcançando atualmente os mais diversos campos do conhecimento (SÁ e QUEIROZ, 2009).

Segundo Herreid (1998), os estudos de casos são histórias com uma determinada mensagem, não são simples narrativas para entretenimento, são histórias para ensinar. As autoras Sá e Queiroz (2009) definem que os casos são narrativas sobre dilemas vivenciados por pessoas que precisam tomar importantes decisões sobre certas questões. Assim, quando familiarizados com o contexto do caso e com seus personagens, os estudantes são impulsionados a tomar decisões.

Segundo Serra e Vieira (2006, p. 10) "Casos são relatos de situações ocorridas no 'mundo real', apresentadas a estudantes com a finalidade de ensinar, preparando-os para a prática". No livro Estudo de Casos no Ensino de Química, as autoras descrevem que:

O estudo de casos é um método que oferece aos estudantes a oportunidade de direcionar sua própria aprendizagem e investigar aspectos científicos e sociocientíficos, presentes em situações reais ou simuladas, de complexidade variável. Esse método consiste na utilização de narrativas sobre dilemas vivenciados por pessoas que necessitam tomar 
decisões importantes a respeito de determinadas questões. Tais narrativas são chamadas casos (SÁ e QUEIROZ, 2009, p. 12).

A aplicação de um estudo de caso é uma estratégia que tem como principais objetivos: a interpretação de textos, resolução de problemas, demonstrar a aplicação de conceitos científicos na prática, estimular a capacidade de tomada de decisão, desenvolvimento interpessoal e em equipe, desenvolver o pensamento crítico e habilidade de comunicação oral e escrita. Segundo Pazinato (2012) para que o estudo de caso alcance suas finalidades é necessário que os estudantes e o professor cumpram algumas tarefas básicas que estão elencadas no Quadro 1, que foi elaborado a partir das ideias de Sá e Queiroz (2009).

Quadro 1 - Tarefas indispensáveis para o bom andamento do estudo de caso.

\begin{tabular}{|c|c|}
\hline Tarefas dos estudantes & Tarefas do professor \\
\hline $\begin{array}{l}\checkmark \text { Identificar e definir o problema; } \\
\checkmark \text { Acessar, avaliar e usar informações } \\
\text { necessárias à resolução do problema; } \\
\checkmark \text { Apresentar a solução do problema. }\end{array}$ & $\begin{array}{l}\checkmark \text { Ajudar o estudante a analisar o } \\
\text { problema, buscar informações sobre o } \\
\text { assunto, considerar suas possíveis } \\
\text { soluções; } \\
\checkmark \text { Incentivar a reflexão sobre as } \\
\text { consequências das decisões tomadas. }\end{array}$ \\
\hline
\end{tabular}

Fonte: Pazinato (2012, p. 37).

Dessa forma e com o intuito de desenvolver nos estudantes as competências e habilidades já mencionadas, nesta pesquisa, foram elaborados e aplicados estudos de casos para os estudantes do ensino médio. Estes casos foram estruturados conforme algumas recomendações sugeridas por Herreid (1998), tais como: abordar um assunto relevante, causar empatia entre os estudantes e os personagens centrais, apresentar fatos controversos, ser pedagogicamente útil, despertar o interesse do leitor, ser atual e curto, provocar um conflito, forçar uma decisão e narrar uma história. Os casos produzidos são relacionados à temática "Tecidos Têxteis".

\section{Metodologia}

O presente trabalho foi desenvolvido e aplicado com 20 estudantes de uma turma de $3^{a}$ série do Ensino Médio de um colégio público localizado na cidade de Santa Maria situada na região central do estado do Rio Grande do Sul. Na sequência, estão descritas as intervenções e as atividades complementares realizadas, necessárias para a aplicação dos estudos de caso. Inicialmente a temática "Tecidos Têxteis" foi apresentada aos estudantes, depois foram distribuídos aos alunos diferentes tipos de tecidos para que pudessem observar suas diferenças e peculiaridades. Utilizando as amostras de tecidos foram levantadas algumas questões para serem discutidas, os estudantes foram questionados sobre que tecidos acreditavam que era cada um deles, se sabiam como surgiram e como são obtidos os tecidos, suas aplicações, a relação com a Química e se conheciam esses tecidos e imaginavam a diversidade de tecidos existentes. 
Na próxima intervenção foi realizada uma revisão das funções orgânicas, amina, álcool, éter, aldeído, cetona, ácido carboxílico, éster e amida. Foram mostradas as imagens de algumas moléculas que fazem parte da composição de alguns tecidos como algodão, linho e sisal. Alguns questionamentos foram levantados para problematizar o tema com os estudantes como:

- Quais tecidos vocês acreditam que são polímeros?

- E os carboidratos será que estão presentes na composição dos tecidos?

- Você sabe o que são polímeros e carboidratos? E como estes podem ser formados?

- Analisando as moléculas dos tecidos estudados vocês podem percebem alguma diferença ou semelhança entre elas? Qual (is)?

- Você imagina que nos tecidos podem ter polímeros e/ou carboidratos?

Estas questões tiveram o intuito de instigar os estudantes a exporem suas concepções sobre esses conceitos que foram estudados no decorrer das atividades e observar se os alunos percebem alguma relação entre os polímeros e carboidratos com os tecidos. Sendo que, muitos questionamentos permaneceram sem resposta e isso foi importante para que os estudantes percebessem a necessidade de mais conhecimentos naquele momento para responder.

Na sequência foi iniciada a abordagem do conteúdo de polímeros, os estudantes foram questionados sobre o entendimento dos mesmos, a partir das respostas que eles forneceram o conceito de polímero foi discutido e explicado, exemplificando com a molécula de celulose, que é um polímero natural presente na composição de tecidos como algodão, linho, sisal entre outros e os estudantes citaram também outros exemplos de polímeros como a sua presença em materiais eletrônicos, no nosso corpo humano, leite, medicamentos, entre outros, também foram abordados os diferentes tipos de polímeros.

$\mathrm{Na}$ intervenção seguinte foram abordados os carboidratos e alguns questionamentos iniciais foram retomados tais como: será que os carboidratos estão presentes na composição dos tecidos, como estes são formados, existe alguma relação com os polímeros e aonde podem ser encontrados. A partir das respostas dos estudantes foram sendo discutidas e explicadas estas questões, e abordou-se as três classes principais: os monossacarídeos, os oligossacarídeos e os polissacarídeos explicando e exemplificando com a molécula de celulose, que é formada a partir do monossacarídeo de glicose na sua forma cíclica ligada através de ligação glicosídica e retomando sobre as funções orgânicas presentes e também abordando a pectina.

Foram formados cinco grupos de estudantes e cada grupo recebeu um estudo de caso diferente, relacionado aos tecidos abordados. Os grupos tiveram espaço para discutir com os colegas em aula e uma semana para pesquisarem e buscarem soluções para o problema a ser resolvido em cada caso. Na sequência estão dois dos casos aplicados aos estudantes, os quais serão analisados neste trabalho.

No caso 1, denominado "O que fazer com os uniformes?" no qual o tecido abordado foi o de algodão está descrito no Quadro 2. O caso 2 (Quadro 3) intitulado "O 
prejuízo de Pedro" relaciona os tecidos de linho e sisal. Os dois casos descritos neste trabalho são fictícios e foram criados pela autora.

Quadro 2 - O caso "O que fazer com os uniformes?"

\begin{abstract}
0 que fazer com os uniformes?
Caibaté é uma cidade pequena que só possui uma loja de confecção de uniforme escolar a Caibaté Confecções. Perto do final do ano, Neila precisou comprar um uniforme novo para seu filho e por isto foi até a loja, sendo atendida por Matheus.

- Bom dia senhora no que posso ajudá-la?

- Bom dia. Estou procurando uma calça e uma camiseta para meu filho da escola Viva, tamanho M.

- Para sua sorte este ano sobraram algumas peças dessa escola.

Ao ir pegar as peças no estoque, o vendedor percebeu que todos os uniformes estavam mofados. Matheus acabou ficando muito preocupado, pois talvez a umidade afetou todo o estoque. Aflito pela situação entrou em contato com os fornecedores do tecido, solicitando auxílio.
\end{abstract}

Dúvida sobre tecido de Algodão $-\varangle \times$ vendatecidos@gmail.com

Dúvida sobre tecido de Algodão

Boa tarde

Me chamo Matheus e sou proprietário da Loja Caibaté Confecções.

Hoje pela manhã fui pegar um uniforme para uma cliente e percebi que todo o estoque da linha de uniformes de algodão, confeccionados com o tecido fornecido pela sua empresa, apresentavam sinais de mofo. Não sabendo como agir, entrei em contato para pedir auxílio em relação a este tecido, como suas propriedades, características e composição para tentar entender o que aconteceu.

Desde já agradeço pela atenção e aguardo retorno o mais rápido possível.

Matheus Rios

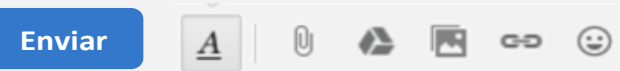

Vocês são os responsáveis técnicos por fornecerem os tecidos, e agora precisam auxiliar Matheus com informações de composição, características e propriedades do tecido para que possa entender o que ocorreu e tentar solucionar o problema. 


\section{O prejuízo de Pedro}

Em um sábado pela manhã Pedro decidiu sair para fazer compras, pois precisava de uma camisa nova e de um tapete para presentear a sua mãe. Foi até uma loja de um shopping em Santa Maria, na qual foi atendido por Roberto.

- Bom dia, posso ajudá-lo?

- Olá, gostaria de ver uma camisa e um tapete.

- Que maravilha hoje a loja tem descontos em camisas de linho, um tecido que dura muito anos.

- Eu gostaria de experimentar uma tamanho M.

- Bem, enquanto procuro a camisa pode olhar os tapetes, nossa loja só vende tapetes de sisal, pois são muito difíceis de serem deteriorados.

Depois de escolher o tapete e experimentar a camisa, Pedro saiu da loja com suas compras e foi presentear sua mãe.

Após uma semana utilizando a camisa, quase todos os dias, Pedro observou que na primeira lavagem, já começou a desgastar e rasgar. E também observaram que o tapete estava desgastando. Então, retornou à loja para reclamar, porém não foi ressarcido do prejuízo. Preocupado e irritado pela falta de atenção, saiu da loja decidido a entrar com uma ação judicial. Porém, precisava além das notas da compra, um laudo técnico com informações sobre os tecidos. Para isso, enviou um e-mail a seu amigo Davi, que é um pesquisador do Colégio Industrial de Santa Maria, o qual é referência em tecidos.

Ajuda sobre tecidos

davi.ctism@gmail.com

Ajuda sobre tecidos

Olá Davi, como você esta?

Olha só, entrei em uma fria, pois comprei uma camisa lindíssima. O vendedor me informou que era de linho e que duraria muito tempo, entretanto na primeira lavada, já desgastou e rasgou. Pior que na mesma loja comprei um tapete para dar de presente a minha mãe, o qual me informaram que é de sisal, acho que realmente estou com muito azar, pois ele também já está desgastando. A loja não quer me ressarcir, desta forma vou entrar com uma ação judicial, só que preciso de um laudo técnico sobre os tecidos, com informações como a sua forma de obtenção, composição química e demais informações que possam ser relevantes para encaminhar a ação. Pois, acredito que a loja está enganando as pessoas, e por isso, preciso da tua ajuda!

Espero tua resposta

Obrigada amigo

Abração

Pedro

Enviar $\underline{A}[0]$

Vocês são o Davi do Colégio Industrial de Santa Maria, amigo de Pedro, e terão que ajudar na elaboração do laudo técnico referente aos tecidos, contendo sua composição química e demais informações pertinentes e ainda dar algumas recomendações para encaminhar ação.

Os estudantes entregaram a resolução do caso de forma escrita e apresentaram oralmente os casos aos colegas bem como as soluções encontradas. Ao longo das apresentações os estudantes foram questionados sobre qual biomolécula formava os 
tecidos apresentados nos casos, qual era o polímero formado e quais as funções orgânicas presentes.

\section{Análise e discussão dos estudos de casos}

Utilizou-se os estudos de casos como estratégia, porque este método possibilita aos sujeitos construírem o seu próprio conhecimento, tendo como objetivo propiciar competências e habilidades como a interpretação de textos, resolução de problemas, tomada de decisão e trabalho em grupo. Este processo ocorre com o auxílio do professor, que passa a ter um papel de coadjuvante, e não mais central, pois se torna um articulador e incentivador na busca da aprendizagem dos seus alunos.

A análise dos resultados será realizada utilizando Análise Textual Discursiva (ATD), que pode ser entendida como um processo auto-organizado de produção de novas compreensões em relação aos fenômenos que examina, na qual as categorias serão a priori e emergentes (MORAES e GALIAZZI, 2006).

Com base nos textos produzidos pelos estudantes para apresentar a resolução dos casos a seguir serão apresentados os casos e discutidos os resultados e as possíveis soluções propostas pelos grupos. Sendo que as seguintes categorias foram criadas para a análise dos casos:

$\checkmark \quad$ Identificação do problema;

$\checkmark \quad$ Abordagem de conceitos científicos;

$\checkmark \quad$ Solução apresentada para o problema.

Um dos casos resolvidos pelos estudantes denominado "O que fazer com os uniformes?" referente ao tecido de algodão, pela análise da carta resposta, pode-se observar que os estudantes identificaram o problema, porém não o mencionaram inicialmente, abordaram vários conceitos químicos apresentando uma solução para o caso, como pode ser observado no Quadro 4, no qual foi realizada a análise a partir das categorias.

\section{Quadro 4 - Análise do caso 1}

\begin{tabular}{|l|}
\hline Identificação do problema \\
\hline Caro Matheus, \\
\hline Abordagem de conceitos científicos \\
\hline O algodão, por conter em sua composição sobretudo moléculas de álcool, realiza \\
ligações fortes de ligação hidrogênio com a água, e por isso a absorve. Pode ser que o \\
ambiente em que você guardava os uniformes estivesse úmido em algum momento, e, \\
por isso, a água proveniente da umidade interagiu com os uniformes de algodão e \\
acarretou na roupa mofada. \\
\hline Solução apresentada para o problema \\
\hline Matheus, para que tu saibas melhor o que aconteceu com os teus uniformes e como \\
solucionar os problemas enfrentados com eles, é necessário que tu entendas mais \\
acerca da composição dos tecidos. Gostaríamos, portanto, que tu comparecesses ao \\
evento sobre tecidos que será realizado em novembro de 2016 , no auditório do Colégio \\
Técnico Industrial de Santa Maria. Assim, tu terás cada vez mais sucesso no teu \\
empreendimento, e poderá obter tua satisfação pessoal e a felicidade dos teus clientes. \\
\hline
\end{tabular}


$\mathrm{Na}$ análise deste caso, podemos perceber que apesar de não mencionar inicialmente o problema na resolução do caso, os estudantes o compreenderam, pois para a solução do mesmo explicam que o tecido de algodão apresenta em sua composição moléculas de álcool. No entanto, não mencionaram qual a composição do tecido que na verdade é basicamente celulose, a qual é formada pela glicose que apresenta em sua estrutura a função álcool a qual tem as hidroxilas $(-\mathrm{OH})$ responsáveis pelas ligações hidrogênio com a água, resultando na absorção da mesma e acarretando o mofo nas peças. Após a explicação não descreveram a solução, porém deixaram entender que se o ambiente em que o cliente guardava os uniformes estivesse úmido em algum momento, a água da umidade iria interagir com os uniformes de algodão e acarretar mofo novamente.

No outro caso aplicado aos estudantes "O prejuízo de Pedro", analisamos a carta resposta dos estudantes podendo-se perceber que conseguiram identificar o problema, utilizando conhecimentos científicos e apresentando uma solução para o caso. Analisamos o caso a partir de categorias criadas a priori, grifada no Quadro 5.

\section{Quadro 5 - Análise do caso 2}

\section{Identificação do problema}

Olá Pedro, tudo bem?

Vou tentar lhe ajudar o máximo, dando uma breve explicação sobre os dois tecidos e em seguida lhe aconselhando.

\section{Abordagem de conceitos científicos}

Segue abaixo o relatório sobre os dois tecidos:

\section{De onde esse tecido é obtido e como é produzido?}

- Linho: É obtido de uma planta e o processo consiste em plantio, colheita, secagem ou fenação (obtem-se a cápsula bem seca), debulhar ou ripagem (separação do caule e da semente) e a fabricação do fio (extração das filaças do caule, secagem, espadelagem (separação completa das fibras do linho), assedagem e por fim, obtém-se o fio (são necessários os acabamentos e a fabricação do tecido).

- Sisal: É obtido de uma planta e o processo consiste em colheita, desfibramento (processo de eliminação da polpa ou mucilagem que envolve a fibra da folha, mediante uma raspagem mecânica), batimento, que consiste em remover o pó que envolve a fibra de Sisal. Essa etapa se processa em máquinas denominadas de batedeiras. Após o batimento a fibra é classificada e enfardada para então ser comercializada.

\section{Qual é a composição química?}

- Linho: celulose, pectina, graxa, cera, substâncias solúveis em água e água.

- Sisal: lignina, pectina, hemicelulose, celulose e cinzas.

\section{Qual é o tipo de polímero?}

- Linho: Celulose + Pectina (formado por monômeros de ácido galacturônico)

- Sisal: Celulose + Pectina (formado por monômeros de ácido galacturônico)

É proteína ou carboidrato?

- Linho: Carboidrato

- Sisal: Carboidrato

Quais as funções orgânicas presentes?

- Linho: Álcool e Aldeído.

- Sisal: Álcool e Aldeído.

Qual o tipo de fibra que compõem esses tecidos? 
- Linho: Fibra têxtil vegetal

- Sisal: Fibra têxtil vegetal

\section{Solução apresentada para o problema}

O linho é extremamente resistente, ele era usado pra embalar múmias, que muitos anos depois eram encontradas com suas "embalagens" intactas, então a loja está enganado os clientes, pois se sua camiseta estragou em uma semana, o tecido não era "puro", pois o linho possui uma durabilidade muito grande, mas para isso, deve-se ter muitos cuidados, entre eles, lavar a seco e a mão, pois a umidade e altas temperaturas fazem com que o tecido fique amarrotado, manchado e sua durabilidade fica comprometida. $\mathrm{O}$ tapete de sisal também é resistente, mas é somente de uso interno, pois não deve ser exposto ao sol ou a umidade, então se vocês não fizeram o bom uso do produto, a culpa não é da loja. Caso você tenha feito os procedimentos corretos, aconselho você a continuar com o processo, caso o contrário, recomendo a desistir de tal ato, pois o erro foi decorrente de mau uso e não de um produto defeituoso.

Convido você para vir ao colégio CTISM, para conversarmos mais sobre o assunto e esclarecer alguma possível duvida ainda restante mesmo após a leitura deste material.

A partir da solução apresentada pelo problema, podemos observar o grande empenho do grupo em pesquisar sobre o assunto, pois inicialmente fizerem um relatório completo sobre os dois tecidos apresentados no caso, descrevendo que são obtidos a partir de fibras têxteis naturais vegetais e o processo de formação do tecido desde a obtenção da fibra. Também apresentaram a composição química de ambas as fibras, que são formadas principalmente por celulose e pectina, que é composta pelo ácido galacturônico, porém não apresentaram as suas estruturas e quando relataram sobre as funções orgânicas presentes destacaram álcool e aldeído, possivelmente por estas fazerem parte da composição da estrutura aberta da glicose que forma a celulose.

Também é importante destacar que os estudantes buscaram uma solução para o caso, expondo as qualidades dos tecidos e argumentando sobre o que poderia ter ocasionado os defeitos, citando que o linho é extremamente resistente e que era usado pra embalar múmias, que depois de muitos anos eram encontradas intactas, desta maneira mostrando que talvez a camisa comprada não fosse de linho puro, pois este tem uma grande durabilidade e também destacaram os cuidados que se deve ter na lavagem para preservar 0 tecido. Sobre 0 tapete de sisal também apresentaram suas características e cuidados que se deve ter com o mesmo e que se esses não foram seguidos, a culpa não seria da loja.

$\mathrm{Na}$ conclusão do caso, destacaram que se Pedro tivesse feito os procedimentos corretos na utilização dos produtos, deveria continuar com o processo, mas ao contrário, recomendaram que desistisse, pois o erro seria pelo mau uso do produto e não de um produto defeituoso.

Após a análise dos casos podemos perceber que os estudantes conseguiram identificar o problema, pesquisando para encontrar uma solução para estes e principalmente que conseguiram abordar conhecimentos científicos na resolução dos casos, descrevendo conteúdos estudados ao longo das intervenções. Segundo Cachapuz et al. (2011), o conhecimento científico deve ser usado na interpretação de fenômenos naturais e de fatos da vida cotidiana, proporcionando a capacidade de reflexão crítica frente à realidade contemporânea. Dessa forma, o processo de aprendizagem torna-se 
eficaz quando possibilita ao estudante a compreensão dos conceitos químicos, bem como a construção do conhecimento científico relacionado com suas aplicações e implicações no contexto social.

Com a resolução e apresentação dos casos também percebeu-se que outras habilidades como capacidade de tomar decisão, comunicação oral e escrita e o pensamento crítico foram estimulados nos estudantes.

É importante ressaltar que ao longo dos anos, houve um grande crescimento do número de publicações envolvendo os estudos de casos no ensino de Química. Dentre estas, podemos destacar o trabalho de Miranda et al. (2014) que utiliza o método em uma $3^{\text {a }}$ série do ensino médio para desenvolver conteúdos de Química, o caso abordado é intitulado "O mistério do assassinato de Marina" e abrange a temática investigação criminal, a autora destaca que "no que se refere à aplicação e à discussão dos conteúdos científicos a partir do problema proposto, observa-se que os estudantes conseguiram propor possíveis soluções baseados nos conteúdos estudados durante as intervenções", bem como que a aplicação do estudo de caso atingiu o proposto inicialmente que foi "estimular inserção à pesquisa e favorecer a tomada de decisão por parte dos estudantes", mostrando resultados semelhantes aos encontrados neste trabalho.

\section{Considerações finais}

O desenvolvimento e aplicação deste trabalho nos mostra que a utilização de metodologias diferenciadas como os estudos de casos tornam-se aliadas para complementar o ensino de conteúdos científicos, favorecendo a construção do conhecimento pelos estudantes. Com a aplicação dos casos "O que fazer com os uniformes?" e "O prejuízo de Pedro", percebemos que a proposta inicial para utilização dessa metodologia de ensino foi alcançada, a qual era estimular a inserção à pesquisa, a capacidade de tomada de decisão por parte dos estudantes, desenvolver o pensamento crítico e a capacidade de trabalhar em grupo.

Um dos intuitos deste trabalho foi relacionar a temática "Tecidos Têxteis" com conteúdos de Química do Ensino Médio. Sendo que proporcionou a contextualização, promovendo a relação entre o dia a dia dos estudantes e os conteúdos químicos abordados, estimulando e despertando o interesse dos alunos, o que contribuiu muito para o processo de ensino e aprendizagem. Desta forma, considera-se que a escolha da temática "Tecidos Têxteis" e da estratégia metodológica proposta neste trabalho foram eficazes e interessantes e podem ser importantes maneiras de minimizar as dificuldades dos estudantes no estudo desta disciplina. Além disso, oportunizar o trabalho em grupo contribuiu para maior integração da turma, pois promoveu uma discussão construtiva entre os alunos, onde os colegas se ajudaram, amadureceram, direcionaram e argumentaram com suas próprias ideias. 


\section{Referências}

ANDRADE, J. E. P., CORREA, A. R., SILVA, C. V. G. F. Pólo de tecelagem plana de fibras sintéticas da região de Americana. Rio de Janeiro: BNDES. fev. 2001. Disponível em:

ww.bndes.gov.br/SiteBNDES/export/sites/default/bndes_pt/Galerias/Arquivos/conheciment o/relato/rs2_gs2.pdf. Acesso em: 12 jul. 2015.

BARBOSA, M. C.; ROSA, S. E. S.; CORREA, A. R.; DVORSAK, P.; GOMES, G. L. Setor de fibras sintéticas e suprimento de intermediários petroquímicos: Complexo têxtil, BNDES Setorial, Rio de Janeiro, n. 20, p. 77-126, set. 2004.

BRAIBANTE, M. E. F.; PAZINATO, M. S. O ensino de Química através de temáticas: contribuições do LAEQUI para a área. Ciência e Natura, v. 36, Ed. Especial II, p. 819 816, 2014.

BRASIL. Ministério da Educação. Secretaria de Educação básica. Orientações Curriculares para o Ensino Médio. Ciências da Natureza, Matemática e suas Tecnologias. v. 2. Brasília, 2006.

BENINI, K. C. C. C. Desenvolvimento e caracterização de compósitos poliméricos reforçados com fibras lignocelulósicas: Hips/fibra da casca do coco verde e bagaço de cana de açúcar. 2011. 125 p. Dissertação (Mestrado em Engenharia Mecânica na área de Materiais) - Universidade Estadual Paulista, Guaratinguetá, 2011.

BERG, J. M.; TYMOCZKO, J. L.; STRYER, L. Bioquímica. 6. ed. Rio de Janeiro: Editora Guanabara Koogan LTDA, 2010, 1114p.

BOBBIO, F. O.; BOBBIO, P. A. Introdução à química dos alimentos. 2. ed. São Paulo: Livraria Varela, 1992. $231 \mathrm{p}$.

BRANDÃO, E. M.; ANDRADE, C. T. Influência de fatores estrturais no processo de gelificação de pectinas de alto grau de metoxilação. Polímeros Ciência e Tecnologia, São Carlos-SP, v.9, n.3, p.38-44, jul/set. 1999.

CACHAPUZ, A.; GIL-PEREZ D.; CARVALHO de, A. M. P.; PRAIA, J.; VILCHES, A. (organizadores). A necessária renovação do ensino de Ciências. 2. ed. São Paulo: Editora Cortez, 2011.

CARVALHO, J. G. Tratamentos térmico e corona em tecido de poliéster. 2011.84 p. Dissertação (Mestrado em Engenharia Química) - Universidade Estadual de Campinas, Campinas, 2011.

CONMETRO. Conselho Nacional de Metrologia, Normalização e Qualidade Industrial. Ministério do Desenvolvimento, Indústria e Comércio Exterior. Resolução no 02 de 6 de maio de 2008, que dispõe sobre a aprovação do regulamento Técnico Mercosul Etiquetagem de Produtos Têxteis, Brasília, DF, 6 maio. 2008.

CORREIA, E. A. S. Compósitos de matriz geopolimérica reforçados com fibras vegetais de abacaxi e de sisal. 2011. 96 p. Tese (Doutorado em Engenharia Mecânica) - Universidade Federal da Paraíba, João Pessoa, PB, 2011. 
COUTEUR, P. L.; BURRESON, J. Os botões de Napoleão: as 17 moléculas que mudaram a história. Rio de Janeiro: Editora Zahar, 2006. 343p.

GUIMARÃES, B. M. G. Estudo das características físico-químicas de fibras têxteis vegetais de espécies de Malvaceae. 2014. 167 f. Dissertação (Mestrado em Ciências) Universidade de São Paulo, São Paulo, 2014.

FENGEL, D.; WEGENER, G. Wood: chemistry, ultrastructure, reactions. New York: Walter de Gruyter, 1989, 612 p.

FERRI, M. G. Plantas produtoras de fibras. São Paulo: Editora Pedagógica e Universitária (E.P.U.), 1976, p.43.

HERREID, C. F. What makes a good case? Journal of College Science Teaching, v. 27, n. 3, p. $163-165$, dez. 1997/jan. 1998.

KUASNE, A. Fibras têxteis: Curso têxtil em malharia e confecção $2^{\circ}$ módulo: apostila. Araranguá: Centro Federal de Educação Tecnológica de Santa Catarina, 2008. 90 p.

LEÃO, M. A. Fibras de licuri: um reforço alternativo de compósitos poliméricos. 2008. 109 p. Dissertação (Mestrado em Engenharia Mecânica) - Universidade Federal do Rio Grande do Norte, Natal, 2008.

MARCONDES, M. E. R.; Proposições metodológicas para o Ensino de Química: Oficinas Temáticas para a Aprendizagem da Ciência e o Desenvolvimento da Cidadania. Revista Em extensão, Uberlândia, vol. 7, p. 67-77, 2008.

MIRANDA, A. C. G.; BRAIBANTE, M. E. F., PAZINATO, M. S., VASCONCELOS, F. O. Atividades Experimentais e Estudo de Caso Aliados a Investigação Criminal: estratégias metodológicas para o Ensino de Química. Revista Brasileira de Ensino de Química, v.9, n. 2, p. 48-60, 2014.

MIÚRA, M.; MUNOZ, S. P. V. Manual técnico têxtil e vestuário: Fibras têxteis. São Paulo: SENAI, 2015.

MORAES, R.; GALIAZZI, M. do C. Análise textual discursiva: processo reconstrutivo de múltiplas faces. Revista Ciência \& Educação, v. 12, n. 1, p. 117-128, 2006.

MOREIRA, M. A.; Teorias de aprendizagem. São Paulo: EPU, 1999.

MWAIKAMBO, L. Y.; ANSELL, M. P. Chemical modification of hemp, sisal, fibers by alkalization. Journal of Applied Polymer Science, United Kingdom, v. 84, p. 2222-2234, 2002.

NELSON, D. L.; COX, M. M. Lehninger princípios de bioquímica. 4. ed. São Paulo: Editora Sarvier, 2006. 1202 p.

PAZINATO, M. S. Alimentos: uma temática geradora do conhecimento químico. 2012. 177 p. Dissertação (Mestrado em Educação em Ciências: Química da Vida e Saúde) - Universidade Federal de Santa Maria, 2012.

PEREIRA, G. S. Materiais e processos têxteis: apostila. Araraguá: Instituto Federal de Educação, Ciências e Tecnologia, 2009. 94 p. 
PEZZOLO, D. B. Tecidos: história, tramas, tipos e usos. São Paulo: Editora Senac São Paulo, 2007. 328p.

SÁ, L. P.; QUEIROZ, S. L. Estudo de Casos no Ensino de Química. Campinas: Editora Átomo, 2009. 95 p.

SANCHES, R. A. Procedimento para o desenvolvimento de tecidos de malha a partir de planejamento de experimentos. 2006. 189 p. Tese (Doutorado Engenharia Mecânica) - Universidade Estadual de Campinas, Campinas, SP, 2006.

SANTOS, W. L. P. dos, MÓL, G. de S.; SILVA, R. R. da; CASTRO, E. N. F. de; SILVA, G. de S.; MATSUNAGA, R. T.; FARIAS, S. B.; SANTOS, S. M. de O.; DIB, S. M. F.; Química e Sociedade: Uma Experiência de Abordagem Temática para o Desenvolvimento de Atitudes e Valores. Revista Química Nova na Escola, São Paulo, n. 20, p. 11-14, nov., 2004.

SILVA, E. L, da; MARCONDES, M. E. R.; Contextualização no ensino de ciências: significados e epistemologia. In: SANTANA, E; SILVA, E. (Org.) Tópicos em Ensino de Química. São Carlos, SP: Editora Pedro e João Editores, 2014.

SILVA, R.; HARAGUCHI, S. K.; MUNIZ, E. C.; RUBIRA, A. F. Aplicações de fibras lignocelulósicas na química de polímeros e compósitos. Química Nova, v. 32, p. 661-67, 2009.

SILVA, A. A organização do trabalho na indústria do vestuário: uma proposta para o setor da costura. 2002. 128 p. Dissertação (Mestrado em Engenharia de Produção) Universidade Federal de Santa Catarina, Florianópolis, 2002.

SERRA, F.; VIEIRA, P. S. Estudos de casos: como redigir, como aplicar. Rio de Janeiro: LTC, 2006.

SORGER, R., UDALE, J. Fundamentos de Design de Moda. Porto Alegre: Bookman, 2009.

ROMERO, L. L.; VIEIRA, J. O. W. M.; MARTINS, R. F.; MEDEIROS, L. A. R. Fibras artificiais e sintéticas. Relato Setorial, Rio de Janeiro, n. 1, p. 1-33, jun. 1995.

Submissão: 07/02/2017

Aceite: $22 / 03 / 2017$ 